\title{
Hypertext tools for implementing evidence-based practice in mental health
}

\author{
Andre Tomlin
}

The recent British Medical Journal series of articles entitled Getting Research into Practice included a paper which described the practice of evidence-based medicine as "a process of lifelong self-directed learning in which caring for patients creates a need for clinically important information about diagnoses, prognoses, treatment, and other healthcare issues" (Straus \& Sackett, 1998). The Centre for Evidence-Based Mental Health located in Oxford, aims to promote and support the teaching and practice of evidencebased mental health (EBMH). Since April 1998 the Centre has been developing a website aimed at two broad groups of users; those who have an active role in teaching evidence-based practice in mental health, and those who wish to find high quality mental health evidence on the Internet. The site contains a wide range of tools to help professionals develop their skills in practising EBMH, as well as tools to enable groups to run training courses in evidence-based practice. In addition to this the site provides a regularly updated list of 'quicklinks' to sources of evidence for the busy mental health care professional.

The most popular sections of the site at present include: the hypertext version of Evidence-Based Mental Health (designed to help mental health clinicians stay up to date with the best available evidence as it is published; Geddes et al, 1998) and the Royal College of Psychiatrists clinical practice guidelines in full-text.

We are also busy developing the web toolkit, which will be made available as it grows, to include (by summer 1999) a number of useful resources. Already available are examples of teaching scenarios for therapy, overviews, diagnosis, prognosis and harm, a module looking at clinical question formulation and information on how to set up an evidence-based journal club.
We are currently developing the finding the evidence module, which will include tutorials on how to search The Cochrane Library, Best Evidence and PubMed (Internet MEDLINE) and OXAMWEB. From spring 1999 you will see the development of the appraising the evidence module, including a wide range of appraisal instruments and mental health critically appraised topics (CATs). By autumn 1999 it will be possible to search our CATbank and NNTbank for clinical bottom line answers to questions. We also hope to have the acting on the evidence module up-and-running before the end of the year, which will include tools to help overcome barriers in implementing evidence-based practice in mental health.

You can visit the centre's website at http:// www.psychiatry.ox.ac.uk/cebmh

\section{References}

GEDDES, J., REYNOLDS, S., StREINER, D., et al (1998) Evidence-based practice in mental health. EvidenceBased Mental Health. 1. 4-5. http://www. psychiatry.ax.ac.uk/cebmh/frames.html

STRAUS. S. E. \& SACKETT, D. L. (1998) Using research findings in clinical practice. British Medical Journal 317. 339-342 http://www.bmy.com/cgi/content/full/ $317 / 7154 / 339$

BEST EVIDENCE <http://www.acponline.org/journals/ebm/ marapr98/bestevid.htmo

СЕВMH http://www.psychiatry.ax.ac.uk/cebmh/

COCHRANE LUBRARY <http://www.update-software.com/ ccweb/cochrane/cdsr.htm>

PUBMED <http://www.ncbi.nlmnih.gov/PubMed/

Andre Tomlin, Director of Knowledge Services, Centre for Evidence-Based Mental Health. Department of Psychiatry, University of Oxford. Warneford Hospital, Oxford OX3 7JX 